\title{
Gender difference in the association between TyG index and subclinical atherosclerosis: results from the I-Lan Longitudinal Aging Study
}

Ya-Wen Lu' ${ }^{1,2,3}$, Chun-Chin Chang ${ }^{2,3^{*}}$, Ruey-Hsing Chou ${ }^{2,3,4}$, Yi-Lin Tsai ${ }^{2,3}$, Li-Kuo Liư ${ }^{5,6}$, Liang-Kung Chen ${ }^{5,6,7,8}$, Po-Hsun Huang ${ }^{2,3,4^{*}}$ and Shing-Jong Lin $2,3,4,9,10$

\begin{abstract}
Background: Insulin resistance (IR) is a known risk factor for cardiovascular disease (CVD) in non-diabetic patients through the association of hyperglycemia or associated metabolic factors. The triglyceride glucose (TyG) index, which was defined by incorporating serum glucose and insulin concentrations, was developed as a surrogate marker of insulin resistance. We aimed to investigate the association between the TyG index and the early phase of subclinical atherosclerosis (SA) between the sexes.

Methods: The I-Lan Longitudinal Aging Study (ILAS) enrolled 1457 subjects aged 50-80 years. For each subject, demographic data and the TyG index \{ln[fasting triglyceride $(\mathrm{mg} / \mathrm{dL}) \times$ fasting plasma glucose $\left.(\mathrm{mg} / \mathrm{dL})] /^{2}\right\}$ were obtained. Patients were further stratified according to sex and the 50th percentile of the TyG index $(\geq 8.55$ or $<8.55)$. SA was defined as the mean carotid intima-media thickness (CIMT) at the 75th percentile of the entire cohort. Demographic characteristics and the presence of SA were compared between the groups. Logistic regression analysis was performed to assess the relationship between TyG index and SA.
\end{abstract}

Results: Patients with a higherTyG index ( $\geq$ 8.55) had a higher body mass index (BMI), hypertension (HTN) and diabetes mellitus (DM). They had higher lipid profiles, including total cholesterol (T-Chol) and low-density lipoprotein $(\mathrm{LDL})$, compared to those with a lower TyG index (< 8.55). Gender disparity was observed in non-diabetic women who had a significantly higher prevalence of SA in the high TyG index group than in the low TyG index group. In multivariate logistic regression analysis, a high TyG index was independently associated with SA in non-diabetic women after adjusting for traditional risk factors [adjusted odds ratio (OR): 1.510, 95\% Cl 1.010-2.257, $p=0.045$ ] but not in non-diabetic men. The TyG index was not associated with the presence of SA in diabetic patients, irrespective of sex.

Conclusion: A high TyG index was significantly associated with SA and gender disparity in non-diabetic patients. This result may highlight the need for a sex-specific risk management strategy to prevent atherosclerosis.

Keywords: TyG index, Insulin resistance, Carotid intima-media thickness

*Correspondence: horawan28@gmail.com; huangbsvgh@gmail.com 2 Division of Cardiology, Department of Medicine, Taipei Veterans General Hospital, Taipei, Taiwan

Full list of author information is available at the end of the article

\section{Introduction}

Insulin resistance (IR), a component of metabolic syndrome (MetS), may precede type 2 diabetes mellitus (T2DM) for decades. It is also an independent risk factor for cardiovascular disease (CVD) in patients without 
T2DM [1-3]. Moreover, IR is responsible for up to $40 \%$ of myocardial infarction and is the most important single risk factor for coronary artery disease (CAD) in young adults [4]. To represent IR, the homeostasis model assessment of IR (HOMA-IR) is a validated and frequently used marker by the incorporation of serum glucose and insulin concentrations. However, it has limited application in clinical practice due to the atypical measurement of serum insulin levels [5]. The fasting triglyceride and glucose (TyG) index was first reported in 2008 as a valuable marker of IR, with a close relationship with HOMA-IR [6]. Numerous clinical studies have shown that a higher TyG index is linked to an increased risk of CVD and a greater prevalence of major adverse cardiovascular events in patients with acute coronary syndrome $[7,8]$.

Carotid intima-media thickness (cIMT) is accepted as an ultrasound marker of early phase subclinical atherosclerosis (SA) and could be a predictive factor of future CVD events $[9,10]$. The well-known determinants of thicker cIMT are age, hypertension (HTN), and sex. Diabetic patients exhibit thicker cIMT than those without DM. In addition, individuals with impaired glucose tolerance but without DM also show a thicker CIMT, although to a lesser extent [11]. Females had a lower thickness of cIMT compared with males in various studies, including the Gutenberg-Heart Study in Germany [12], Atherosclerosis Risk in Communities (ARIC) study [13], and the Suita study for Japanese subjects [14].

Sex disparities exist in glucose metabolism. As previous studies have shown, T2DM is a greater risk factor for ischemic heart disease in women than in men. Impaired glucose tolerance is more prevalent in women [15]. However, clinical investigations on the impact of IR on the early phases of SA between men and women remains scarce. The purpose of this study was to investigate whether the TyG index, as a surrogate marker for IR, is associated with the early phase of SA. We also investigated whether sex disparities exist, especially in the nondiabetic stage.

\section{Methods}

\section{Study population}

The present cross-sectional study was conducted with participants from the first wave of the I-Lan Longitudinal Aging Study (ILAS). The ILAS is a research cohort of community-dwelling adults aged > 50 years who were randomly recruited through household registration records. Inhabitants who met the study inclusion criteria were randomly sampled from the household registration data of the county government. Selected inhabitants were invited to participate via mail or telephone. The inclusion criteria were (1) those having no plans to move out of I-Lan County in the near future and (2) those aged 50 years or older. Details of the ILAS design, participant recruitment, and data collection have been reported previously [16]. The participants were excluded from this study if any of the following conditions were met: (i) they were unable to cooperate or communicate with study investigators, (ii) they declined to grant consent, (iii) they were currently institutionalized, or had any known active disease, such as active cancer, sepsis, heart failure, chronic obstructive pulmonary disease, or functional dependence; (v) they had a life expectancy of less than six months; or (vi) they planned to leave I-Lan county. A total of 1839 community-dwelling older adults were enrolled between August 2011 and August 2013. All participants provided written informed consent after receiving inperson face-to-face interviews with well-trained research nurses. Among them, 382 subjects were excluded, including 88 with CAD, 105 taking lipid-lowering agents, 91 older than 80 years, and 98 with incomplete data (Fig. 1). The study was conducted in accordance with the Declaration of Helsinki and was approved by the Institutional Review Board of the National Yang Ming Chiao Tung University (YM103008).

\section{Anthropometry, demographic measurements, and laboratory examinations}

A research nurse used a questionnaire to collect data regarding demographics, years of education, smoking habits, and other elements of the participants' medical histories. The height, weight, and resting blood pressure (BP) of each subject were measured. Brachial blood pressure was measured with a mercury sphygmomanometer after the subjects had rested for at least $15 \mathrm{~min}$. Basic medical history elements, including underlying diseases, medication, and smoking, were obtained from personal interviews, and recorded in the medical notes. After fasting for at least $10 \mathrm{~h}$, peripheral blood samples were collected from 7 to $9 \mathrm{AM}$ to determine the concentrations of hemoglobin A1c (HbA1c), fasting blood glucose (FBG), T-Chol, high-density lipoprotein (HDL), LDL, triglyceride (TG), uric acid (UA), and high-sensitivity C-reactive protein (hsCRP) using an automatic analyzer (ADVIA 1800; Siemens, Malvern, PA, USA).

Metabolic syndrome (MetS) was defined according to the criteria proposed by Taiwan's Ministry of Health and Welfare. More than three of the following risk determinants were included: (i) waist circumference $>90 \mathrm{~cm}$ for men or $>80 \mathrm{~cm}$ for women; (ii) systolic blood pressure $\geq 130 \mathrm{mmHg}$, diastolic blood pressure $\geq 85 \mathrm{mmHg}$, or use of antihypertensive agents; (iii) HDL $<40 \mathrm{mg} / \mathrm{dL}$ for men or $<50 \mathrm{mg} / \mathrm{dL}$ for women; $\mathrm{TG} \geq 150 \mathrm{mg} / \mathrm{dL}$; (iv) FBG $\geq 100 \mathrm{mg} / \mathrm{dL}$ or use of antihyperglycemic agents. Chronic kidney disease (CKD) was defined as an eGFR 


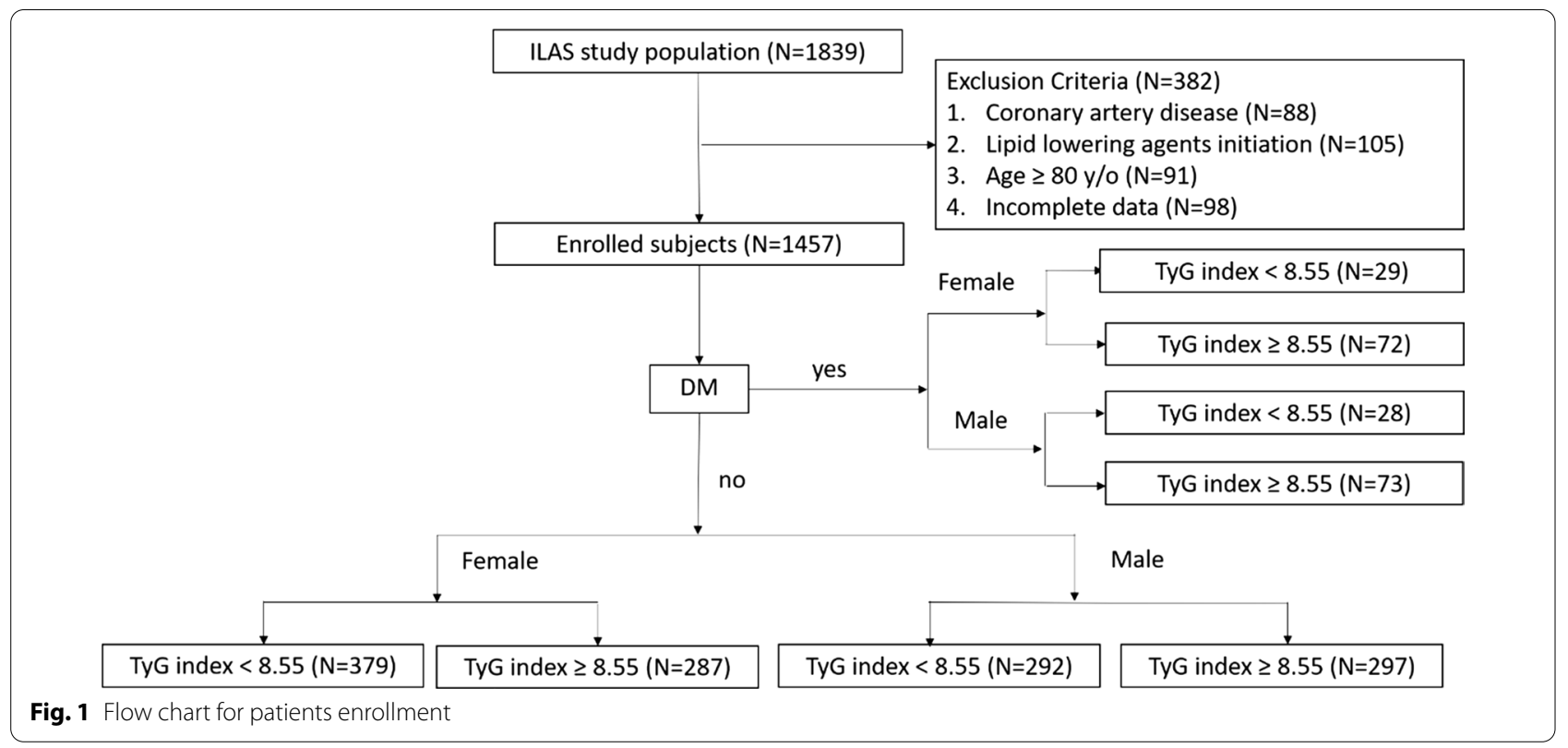

$<60$, which was calculated using the Chronic Kidney Disease Epidemiology Collaboration equation [17]. Individuals were defined as overweight by a BMI more than 25.0 from the WHO uniform categories of BMI [18]. The TyG index was calculated using the following formula: $\ln$ [fasting triglyceride $(\mathrm{mg} / \mathrm{dL}) \times$ fasting plasma glucose $\left.(\mathrm{mg} / \mathrm{dL}) /^{2}\right][6]$. The optimal cut-off value of the TyG index to define insulin resistance has not yet been standardized. Similar to previously published studies $[19,20]$, we used the median value of the TyG index (8.55) to stratify the study population. A flowchart of patient enrollment and classification is illustrated in Fig. 1.

\section{Assessment of carotid intima-media thickness (cIMT) and subclinical atherosclerosis (SA)}

The cIMT was measured using a high-resolution, broadwidth, linear array transducer (LOGIQ 400 PRO; GE, Cleveland, OH, USA) at the level of the common carotid artery. All examinations were performed by the same trained technician, who measured the arteries, including the proximal to distal sections of the bilateral common carotid arteries on longitudinal views [21]. The mean cIMT was defined as the average of the right-and left-side cIMT values. The 75th percentile of cIMT was defined as the upper limit to be considered normal, which was the threshold indicative of increased cardiovascular risk and the early phase of SA [10, 22-24]. In the present study, the 75th percentile of cIMT was $0.75 \mathrm{~mm}$.

\section{Statistical analysis}

Data were expressed as frequencies (percentages) for categorical variables and as means \pm standard deviations for continuous variables with normal distribution and as median with interquartile range due to the non-normal distribution. The chi-square test was used for comparisons between two groups of categorical variables. The independent $t$ test was employed for continuous variables with normal distribution. The Kruskal-Wallis test was used for non-normally distributed continuous variables. Pearson and Spearman's tests were used to assess the correlation between the TyG index and cIMT with other variables. Associations between factors and SA were expressed as odds ratios (ORs). Factors that were significant in univariate regression analysis $(p<0.05)$ were entered into the multivariate regression analysis to evaluate the relationship between the TyG index and SA. Odds ratios with $95 \%$ confidence intervals $(95 \% \mathrm{CI})$ for the risk of cIMT $\geq 0.75 \mathrm{~mm}$ were reported. Statistical analyses were performed using SPSS (version 22.0; IBM Corporation, Armonk, New York, USA). Two-tailed $p$ values $<0.05$, were regarded as statistically significant.

\section{Results}

A total of 1457 patients $(47.4 \%$ men; mean age $62.34 \pm 8.00$ years) without CAD, without lipid-lowering agents and less than 80 years old, were investigated. Compared with the lower TyG index (TyG index < 8.55) group, patients with a higher TyG index (TyG index $\geq 8.55$ ) were more often male, had a higher waist circumference, and a higher prevalence of being overweight (BMI $\geq 25.0$ ). They exhibited MetS, DM, and HTN. The values of lipid profiles including T-chol, LDL, TG, FBG, and HbA1c were significantly increased in the high TyG index group. There was no difference in 
age, CKD, or smoking history between the two groups. The mean cIMT was $0.68 \pm 0.13 \mathrm{~mm}$ and significantly thicker in the higher TyG index group. The percentage of cIMT more than $0.75 \mathrm{~mm}$, as the 75th percentile of the whole analyzed group was significantly higher in the higher TyG index group, as shown in Table 1.

Figure 2 shows the correlation coefficients between the TyG index and cIMT with other variables. Male sex, smoking, HTN, DM, MetS, BMI, antihypertensive drug usage, total cholesterol, uric acid, and hsCRP were positively correlated with both the TyG index and cIMT. Meanwhile, serum HDL levels were negatively correlated with both the TyG index and cIMT. LDL levels were only positively correlated with the TyG index and not with cIMT. In addition, age and CKD were only positively correlated with cIMT, not the TyG index. The values of correlation coefficients of TyG index and cIMT are shown in Additional file 1: Table S1.
We stratified the subjects into non-diabetes and diabetes groups between the sexes. For nondiabetic subjects, as shown in Table 2, a greater prevalence of MetS, those that were overweight, had higher levels of T-chol, HbA1c, $\mathrm{UA}$, and a significantly lower HDL were found in the higher TyG index group. This was the case for both males and females (all $p$ values $<0.05$ ). However, a greater prevalence of hypertension $(24.3 \%$ vs. $37.6 \%, p$ value $<0.001)$, a significantly thicker cIMT $(0.64 \pm 0.11 \mathrm{~mm}$ vs. $0.67 \pm 0.11 \mathrm{~mm}, p=0.006)$, and a higher prevalence of SA $(17.2 \%$ vs. $25.4 \%, p=0.012)$ was observed only in non-diabetic females with a higher TyG index than in subjects with a lower index. For diabetic populations, as Additional file 2: Table S2, both men and women had a higher prevalence of MetS, a greater T-chol level, and a lower HDL. However, only female subjects had significantly higher BMI, LDL, and HbA1c in the higher TyG index population. There was no difference in the prevalence of hypertension, CKD, or individuals who were

Table 1 Baseline characteristics stratified by TyG index of entire population stratified by lower and higher TyG index

\begin{tabular}{|c|c|c|c|c|}
\hline & Total cases; $n=1457$ & TyG index $<8.55 ; \mathrm{n}=728$ & TyG index $\geq 8.55 ; \mathrm{n}=729$ & $p$ value \\
\hline Age (years) & $62.34 \pm 8.00$ & $62.31 \pm 8.06$ & $62.37 \pm 7.95$ & 0.894 \\
\hline Female/male (\%) & $767 / 690(52.6 / 47.4)$ & $408 / 320(56.0 / 44.0)$ & $359 / 370(49.2 / 50.8)$ & 0.010 \\
\hline $\mathrm{BMI}$ & $24.81 \pm 3.55$ & $23.55(21.66-25.79)$ & $25.35(23.42-27.65)$ & $<0.001$ \\
\hline Waist circumference & $84.28 \pm 9.75$ & $81.5(75.0-88.0)$ & $86.5(80.0-93.0)$ & $<0.001$ \\
\hline Smoking (\%) & $260(17.8)$ & $117(16.1)$ & $143(19.6)$ & 0.087 \\
\hline \multicolumn{5}{|l|}{ Underlying disease } \\
\hline Hypertension (\%) & $520(35.7)$ & $212(29.1)$ & $308(42.2)$ & $<0.001$ \\
\hline Anti-hypertensive agents (\%) & $239(16.4)$ & $93(12.8)$ & $146(20.0)$ & $<0.001$ \\
\hline $\mathrm{DM}(\%)$ & $202(13.9)$ & $57(7.8)$ & $145(19.9)$ & $<0.001$ \\
\hline CKD (\%) & $282(19.4)$ & $129(17.8)$ & $153(21.0)$ & 0.127 \\
\hline Metabolic syndrome (\%) & $453(31.1)$ & $90(12.4)$ & $363(49.8)$ & $<0.001$ \\
\hline Overweight (\%) & $633(43.4)$ & $239(32.8)$ & $394(54.0)$ & $<0.001$ \\
\hline LDL $\geq 130$ mg/dL (\%) & $554(38.0)$ & $239(32.8)$ & $315(43.2)$ & $<0.001$ \\
\hline \multicolumn{5}{|l|}{ Laboratory data } \\
\hline Total cholesterol (mg/dl) & $197.66 \pm 35.30$ & $193(168-215)$ & $202(177-223)$ & $<0.001$ \\
\hline $\mathrm{HDL}(\mathrm{mg} / \mathrm{dl})$ & $55.16 \pm 14.11$ & $58(50-69)$ & $49(42-56)$ & $<0.001$ \\
\hline $\mathrm{LDL}(\mathrm{mg} / \mathrm{dl})$ & $120.87 \pm 32.57$ & $116(96-137)$ & $124(102-144)$ & $<0.001$ \\
\hline Fasting glucose (mg/dl) & $101.49 \pm 28.16$ & $92(87-98)$ & $100(92-111)$ & $<0.001$ \\
\hline $\mathrm{HbA1c}(\%)$ & $6.01 \pm 0.98$ & $5.7(5.5-6.0)$ & $5.9(5.6-6.4)$ & $<0.001$ \\
\hline Uric acid & $5.84 \pm 1.50$ & $5.4(4.6-6.3)$ & $6.1(5.1-7.1)$ & $<0.001$ \\
\hline hs-CRP & $0.22 \pm 0.38$ & $0.069(0.033-0.190)$ & $0.102(0.041-0.245)$ & 0.975 \\
\hline Triglyceride (mg/dl) & $121.85 \pm 78.47$ & $77(60-90)$ & $143(123-186)$ & $<0.001$ \\
\hline $\operatorname{eGFR}\left(\mathrm{ml} / \mathrm{min} / 1.73 \mathrm{~m}^{2}\right)$ & $83.33 \pm 28.30$ & $82.62 \pm 27.24$ & $84.03 \pm 29.32$ & 0.341 \\
\hline Triglyceride glucose index & $8.57 \pm 0.58$ & $8.18(7.95-8.36)$ & $8.88(8.70-9.21)$ & $<0.001$ \\
\hline Mean cIMT (mm) & $0.68 \pm 0.13$ & $0.65(0.60-0.75)$ & $0.70(0.60-0.75)$ & 0.003 \\
\hline $\mathrm{cIMT} \geq 0.75$ mm (\%) & $417(28.6)$ & $189(26.0)$ & $228(31.3)$ & 0.028 \\
\hline
\end{tabular}

Values are mean \pm standard deviation or $n(\%)$

$B M I$ body mass index, DM diabetes mellitus, $C K D$ chronic kidney disease, $H D L$ high density lipoprotein, $L D L$ low density lipoprotein, $H b A 1 c$ hemoglobin A1c, $h s$ - $C R P$ high sensitivity C-reactive protein, eGFR estimated glomerular filtration rate, CIMT carotid intima-media thickness

${ }^{\text {a }}$ Triglyceride glucose index $=\ln [$ fasting $T G(\mathrm{mg} / \mathrm{dL}) \times$ fasting plasma glucose $(\mathrm{mg} / \mathrm{dL}) / 2]$ 


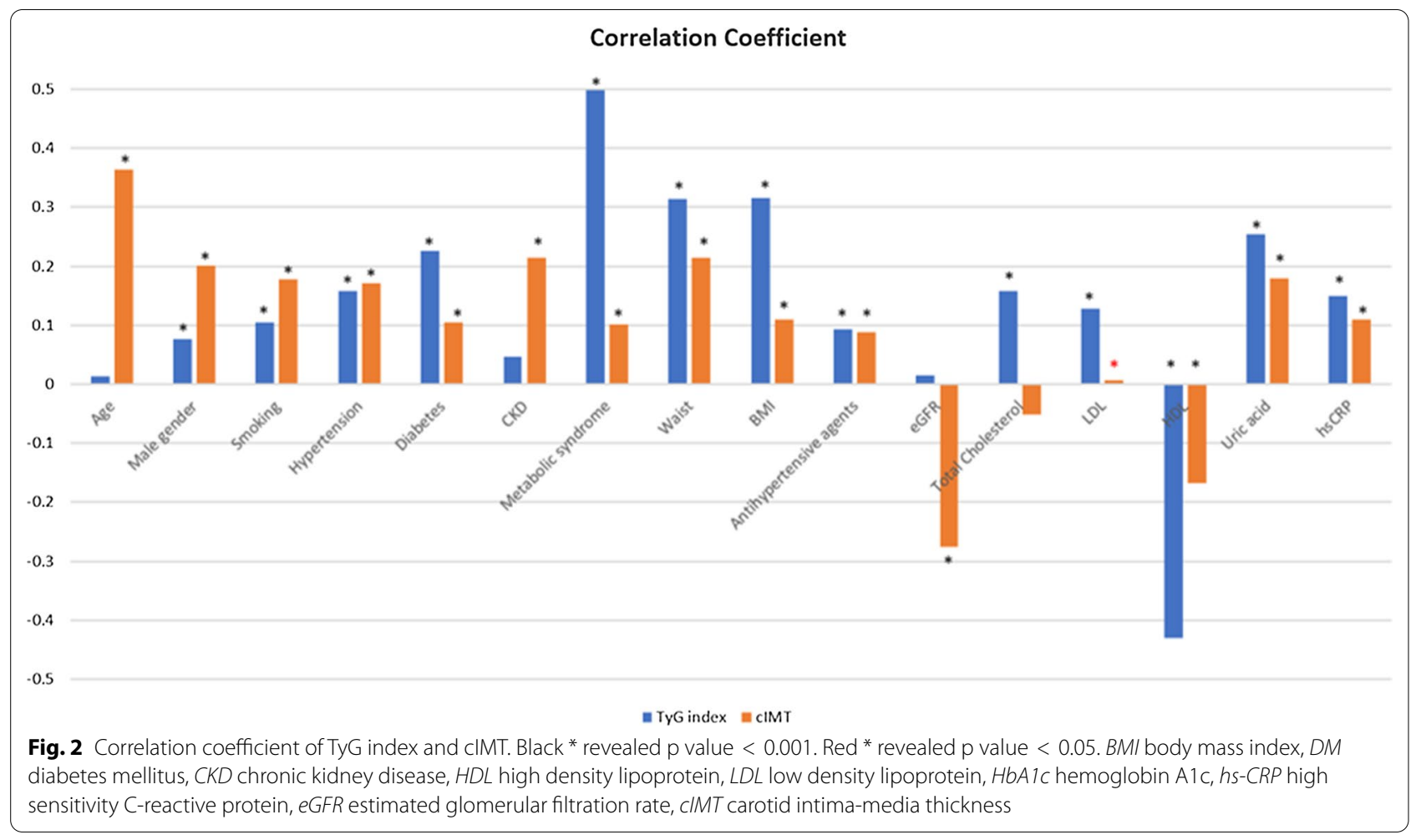

overweight. There was no cIMT value difference in diabetic females or males stratified by a lower or higher TyG index.

Sex disparities were observed in non-diabetic patients (Table 3). Multivariate logistic regression analysis for non-diabetic women showed that a higher TyG index [adjusted odds ratio (aOR): 1.510, 95\% CI 1.010-2.257], age (aOR: 1.099, 95\% CI 1.070-1.128) and HTN (aOR: 1.689, 95\% CI 1.115-2.559) were independently associated with SA (defined as cIMT $\geq$ $0.75 \mathrm{~mm}$ ) after adjusting for confounding factors. For nondiabetic men, the independent factors related to SA (defined as cIMT $\geq 0.75 \mathrm{~mm}$ ) were age (aOR, 1.094; 95\% CI 1.067-1.122) and BMI (aOR: 1.118, 95\% CI 1.051-1.190). A higher TyG index was significantly associated with cIMT $\geq 0.75 \mathrm{~mm}$ in non-diabetic women, however not in non-diabetic men. The $p$ for the interaction between the TyG index and gender $=$ 0.045 (Fig. 3).

\section{Discussion}

Our results showed that a higher TyG index (TyG index $\geq 8.55$ ) was significantly associated with SA (cIMT $\geq 0.75 \mathrm{~mm}$, as the 75th percentile of the study population) compared with a lower TyG index (TyG index $<8.55)$ in women. In addition, the influence of a higher TyG index and SA was only observed in nondiabetic women, however not in nondiabetic men.

\section{Current evidence of insulin resistance, TyG index, and cIMT}

IR is linked to atherosclerosis through metabolic abnormalities, such as hyperglycemia, dyslipidemia, and hyperinsulinemia [25]. HOMA-IR as a surrogate marker of hepatic insulin resistance has been investigated regarding plaque progression in CAD [26]. The disadvantage of the application of HOMA-IR is the atypical measurement of serum insulin levels. The TyG index, as the product of fasting glucose and TG, was strongly associated with HOMA-IR and insulinstimulated glucose uptake measured as the steady-state plasma glucose concentration during insulin suppression testing $[6,27]$.

Previous studies have focused on the role of the TyG index in progressive diseases such as carotid atherosclerosis or CVD. This includes CAD, stroke, or peripheral artery disease $[28,29]$. Our study provides evidence of the TyG index and the link to SA in a relatively healthy population of middle to old age. We separated the population into women and men due to the excess risk of vascular complications conferred by DM in women [30, 31]. The present study is the first to indicate that gender disparities in the association with SA exist in non-diabetic individuals when the TyG index is increased. 
Table 2 Baseline characteristics according to lower and higher TyG index in nondiabetic population stratified by gender

\begin{tabular}{|c|c|c|c|c|c|c|}
\hline & \multicolumn{3}{|l|}{ Female } & \multicolumn{3}{|l|}{ Male } \\
\hline & $\begin{array}{l}\text { Lower TyG index; } \mathbf{n} \\
=379\end{array}$ & $\begin{array}{l}\text { Higher TyG index; } \mathbf{n} \\
=287\end{array}$ & $p$ value & $\begin{array}{l}\text { Lower TyG index; } n \\
=292\end{array}$ & $\begin{array}{l}\text { Higher TyG index; } \mathbf{n} \\
=297\end{array}$ & $p$ value \\
\hline Age (years) & $60.94 \pm 7.61$ & $61.71 \pm 7.64$ & 0.198 & $63.29 \pm 8.21$ & $62.26 \pm 8.18$ & 0.126 \\
\hline $\mathrm{BMI}$ & $23.23(21.22-25.36)$ & $24.79(22.92-27.50)$ & $<0.001$ & $23.78(21.97-25.85)$ & $25.52(23.32-27.20)$ & $<0.001$ \\
\hline Waist circumference & $78.5(72-85)$ & $83(78-90)$ & $<0.001$ & $84(79-90)$ & $88(83-94)$ & $<0.001$ \\
\hline Smoking (\%) & $9(2.4)$ & $12(4.2)$ & 0.262 & 99 (33.9) & $101(34.0)$ & 1.000 \\
\hline \multicolumn{7}{|l|}{ Underlying disease } \\
\hline Hypertension (\%) & $92(24.3)$ & $108(37.6)$ & $<0.001$ & $86(29.5)$ & $102(34.3)$ & 0.216 \\
\hline $\begin{array}{l}\text { Anti-hypertensive } \\
\text { agents (\%) }\end{array}$ & $42(11.1)$ & $42(14.6)$ & 0.195 & $35(12.0)$ & $54(18.2)$ & 0.039 \\
\hline CKD (\%) & $16(4.2)$ & $20(7.0)$ & 0.165 & $97(33.4)$ & $94(31.6)$ & 0.660 \\
\hline $\begin{array}{l}\text { Metabolic syndrome } \\
(\%)\end{array}$ & $41(10.8)$ & $141(49.1)$ & $<0.001$ & $22(7.5)$ & $109(36.7)$ & $<0.001$ \\
\hline Overweight (\%) & $110(29.0)$ & $136(47.4)$ & $<0.001$ & $102(34.9)$ & $165(55.6)$ & $<0.001$ \\
\hline $\mathrm{LDL} \geq 130$ mg/dL (\%) & $134(35.4)$ & $144(50.2)$ & $<0.001$ & $96(32.9)$ & $133(44.8)$ & 0.003 \\
\hline \multicolumn{7}{|l|}{ Laboratory data } \\
\hline $\begin{array}{l}\text { Total cholesterol (mg/ } \\
\text { dl) }\end{array}$ & $202(179-222)$ & $211(191-233)$ & $<0.001$ & $186(165-209)$ & $198(177-218)$ & $<0.001$ \\
\hline $\mathrm{HDL}(\mathrm{mg} / \mathrm{dl})$ & $64(54-74)$ & $53(46-60)$ & $<0.001$ & $53(46-62)$ & $47(40-53)$ & $<0.001$ \\
\hline LDL (mg/dl) & 118 (98-139) & $130(110-151)$ & $<0.001$ & $117(97-137.8)$ & $124(101.5-143)$ & 0.028 \\
\hline Fasting glucose (mg/dl) & $91(86-96)$ & $97(91-105)$ & $<0.001$ & $92(88-98)$ & $96(90.5-104)$ & $<0.001$ \\
\hline HbA1c (\%) & $5.7(5.5-5.9)$ & $5.9(5.6-6.2)$ & $<0.001$ & $5.7(5.4-5.9)$ & $5.7(5.5-6.0)$ & $<0.001$ \\
\hline Uric acid & $4.9(4.2-5.6)$ & $5.4(4.6-6.3)$ & $<0.001$ & $6.1(5.3-6.9)$ & $6.7(5.9-7.7)$ & $<0.001$ \\
\hline hs-CRP & $0.067(0.031-0.179)$ & $0.101(0.03-0.240)$ & 0.001 & $0.24 \pm 0.48$ & $0.21 \pm 0.36$ & 0.361 \\
\hline Triglyceride (mg/dl) & $78(60-91)$ & $141(124-176)$ & $<0.001$ & $76(62-90)$ & $150(124.5-204.5)$ & $<0.001$ \\
\hline $\operatorname{eGFR}\left(\mathrm{ml} / \mathrm{min} / 1.73 \mathrm{~m}^{2}\right)$ & 90.98 (72.30-108.23) & $100.30(79.22-114.24)$ & 0.010 & $67.01 \pm 18.54$ & $70.13 \pm 20.26$ & 0.052 \\
\hline $\begin{array}{l}\text { Triglyceride glucose } \\
\text { index }\end{array}$ & $8.17(7.90-8.35)$ & $8.83(8.67-9.07)$ & $<0.001$ & $8.18(7.96-8.35)$ & $8.88(8.71-9.21)$ & $<0.001$ \\
\hline Mean cIMT (mm) & $0.64 \pm 0.11$ & $0.67 \pm 0.11$ & 0.006 & $0.71 \pm 0.16$ & $0.71 \pm 0.14$ & 0.698 \\
\hline $\mathrm{CIMT} \geq 0.75 \mathrm{~mm}$ & $65(17.2)$ & $73(25.4)$ & 0.012 & $105(36.0)$ & $99(33.3)$ & 0.545 \\
\hline
\end{tabular}

Values are mean \pm standard deviation or $n(\%)$

$B M I$ body mass index, DM diabetes mellitus, $C K D$ chronic kidney disease, $H D L$ high density lipoprotein, $L D L$ low density lipoprotein, $H b A 1 c$ hemoglobin A1c, $h s$ - $C R P$ high sensitivity C-reactive protein, eGFR estimated glomerular filtration rate, CIMT carotid intima-media thickness

${ }^{\text {a }}$ Triglyceride glucose index $=\ln \left[\right.$ fasting TG $(\mathrm{mg} / \mathrm{dL}) \times$ fasting plasma glucose $\left.(\mathrm{mg} / \mathrm{dL}) /{ }^{2}\right]$

\section{Sex difference in CHD risk and insulin resistance}

Our study showed that the TyG index correlated with metabolic parameters, including waist circumference, HDL, and blood pressure, is in agreement with previous studies. Insulin resistance (or metabolic) syndrome and further cardiovascular complications are believed to be related to adipokines. These include tumor necrosis factor-alpha (TNF- $\alpha$ ) and dysregulation. These are involved in the decreased production of nitric oxide in vascular endothelial cells, thus promoting atherosclerosis [32]. The TyG index has been associated with incident hypertension, possibly through insulin resistance-related hyperinsulinemia. This increases sympathetic nervous system activity or activation of the renin-angiotensin-aldosterone system [33, 34].
Women experience greater changes in the rates of BMI and deterioration of lipid profiles compared to men, even when cardiovascular risk factors (CVRF) are similar [35]. The difference between men and women in the preferred location of fat storage could play a role in the development of IR and diabetes [36-38]. Unlike men with more fat stores in the abdominal region with a substantially higher amount of visceral and ectopic fat [39, 40], women are more likely to store fat subcutaneously [41]. As visceral fat is strongly associated with insulin resistance, women may need to gain more weight and experience more significant deterioration of related metabolic risk factors than men to reach the same level of visceral fat storage [42]. This means that sex differences in metabolic risk factors already occur during the transition from 
Table 3 Univariate and multivariate logistic regression analysis of factors associated with the incidence of cIMT $\geq 0.75 \mathrm{~mm}$ (75th percentile) in non-DM patients $(n=1255)$

\begin{tabular}{|c|c|c|c|c|c|c|}
\hline \multirow[t]{2}{*}{ Variable } & \multicolumn{3}{|c|}{ Univariate analysis } & \multicolumn{3}{|c|}{ Multivariate analysis } \\
\hline & OR & $95 \% \mathrm{Cl}$ & $p$ value & OR & $95 \% \mathrm{Cl}$ & $p$ value \\
\hline \multicolumn{7}{|l|}{ Female $(n=666)$} \\
\hline Higher TyG index & 1.648 & $1.131-2.402$ & 0.009 & 1.510 & $1.010-2.257$ & 0.045 \\
\hline Age & 1.106 & $1.078-1.135$ & $<0.001$ & 1.099 & $1.070-1.128$ & $<0.001$ \\
\hline BMl & 1.055 & $1.003-1.109$ & 0.038 & 1.000 & $0.940-1.063$ & 0.995 \\
\hline Smoking & 1.962 & $0.776-4.959$ & 0.154 & & & \\
\hline Hypertension & 2.397 & $1.627-3.532$ & $<0.001$ & 1.689 & $1.115-2.559$ & 0.013 \\
\hline CKD & 2.597 & $1.292-5.520$ & 0.007 & 1.061 & $0.481-2.338$ & 0.884 \\
\hline Anti-hypertensive agents & 1.531 & $0.909-2.578$ & 0.109 & & & \\
\hline Total cholesterol & 1.004 & $0.998-1.009$ & 0.173 & & & \\
\hline $\mathrm{HDL}$ & 0.990 & $0.977-1.004$ & 0.167 & & & \\
\hline LDL & 1.004 & $0.999-1.010$ & 0.138 & & & \\
\hline UA & 1.293 & $1.115-1.499$ & 0.001 & 1.117 & $0.947-1.317$ & 0.189 \\
\hline hs-CRP & 1.277 & $0.751-2.172$ & 0.367 & & & \\
\hline \multicolumn{7}{|l|}{ Male $(n=589)$} \\
\hline Higher TyG index & 0.890 & $0.634-1.251$ & 0.503 & & & \\
\hline Age & 1.086 & $1.062-1.111$ & $<0.001$ & 1.094 & $1.067-1.122$ & $<0.001$ \\
\hline $\mathrm{BMI}$ & 1.062 & $1.007-1.119$ & 0.026 & 1.118 & $1.051-1.190$ & $<0.001$ \\
\hline Smoking & 0.958 & $0.669-1.373$ & 0.816 & & & \\
\hline Hypertension & 2.022 & $1.413-2.894$ & $<0.001$ & 1.319 & $0.867-2.006$ & 0.196 \\
\hline CKD & 1.654 & $1.157-2.365$ & 0.006 & 0.991 & $0.601-1.635$ & 0.972 \\
\hline Anti-hypertensive agents & 1.200 & $0.753-1.912$ & 0.443 & & & \\
\hline Total cholesterol & 0.999 & $0.994-1.004$ & 0.787 & & & \\
\hline $\mathrm{HDL}$ & 0.992 & $0.978-1.005$ & 0.229 & & & \\
\hline LDL & 1.002 & $0.997-1.008$ & 0.373 & & & \\
\hline UA & 1.123 & $0.996-1.265$ & 0.058 & 1.002 & $0.890-1.173$ & 0.763 \\
\hline hs-CRP & 1.725 & $1.116-2.668$ & 0.014 & 1.471 & $0.945-2.289$ & 0.087 \\
\hline
\end{tabular}

$C K D$ chronic kidney disease; $L D L$ low-density lipoprotein; $H D L$ high-density lipoprotein; $U A$ uric acid; $h S C R P$ high-sensitivity C-reactive protein

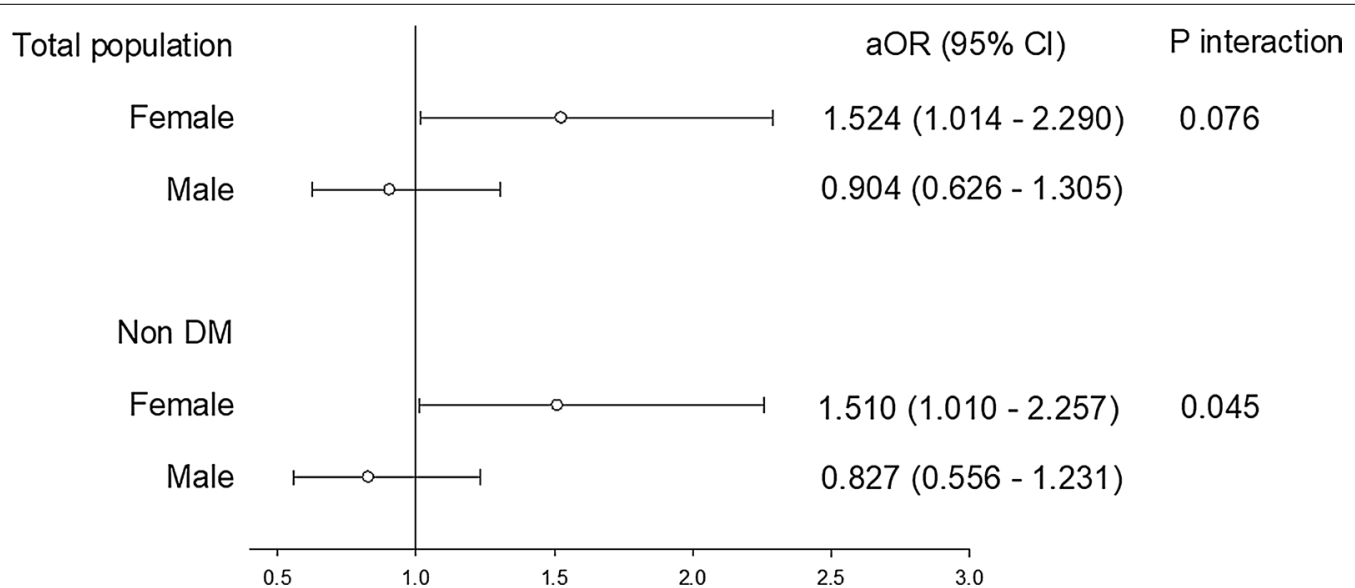

Fig. 3 Gender disparity in whole population and non-DM group. aOR adjusted odds ratio, variables adjusted: age, BMI, HTN, CKD, UA, hsCRP 
normoglycemia to elevated glucose levels and diabetes [31].

In the present study, a higher TyG index in non-diabetic women was significantly associated with SA compared with non-diabetic men. There was no sex disparity in the diabetic group. Enrolled subjects were older than 50 years of age; most women were in late perimenopause or menopause. Endogenous estrogen may play a role in higher insulin sensitivity in females in a rodent model [43]. In large clinical studies, menopausal hormone therapy for postmenopausal women may improve insulin sensitivity through estrogen receptors in the liver, muscle, and adipose tissue [44, 45]. The protective effect of estrogen is eliminated when females have the following risk factors: high ratios of total/high-density lipoprotein cholesterol level ratios, left ventricular hypertrophy, or diabetes [46, 47]. Moreover, not only in DM patients, but also among non-diabetic subjects, women had greater CVD events and death than men. They also had greater effects from a higher TG and blood pressure [15, 47]. In the present study, the greater prevalence of HTN observed in nondiabetic women was consistent with previous studies. The relationship between TyG index and cIMT in nondiabetic women requires further investigation.

\section{Study limitations}

The limitations of our study are as follows: first, due to the retrospective, observational study design, the causal relationship between higher TyG index and SA could not be fully assessed. Second, certain confounding factors, such as duration of diabetes, categories of anti-diabetic agents, or insulin use were not considered in the present study. Third, the cross-sectional cohort study lacked long-term outcome data such as longitudinal studies. Thus, we could not investigate the impact of the TyG index on the risk of new-onset CVD. Fourth, the optimal cut-off value of the TyG index to define insulin resistance has not yet been standardized and may vary between study populations. Lastly, the exploration of the mechanism linking the TyG index and atherosclerosis is beyond the scope of this study.

\section{Conclusions}

In this cross-sectional study, a high TyG index was significantly associated with SA with disparities by sex in non-diabetic patients after adjusting for the traditional risk factors of atherosclerosis. Our findings suggest a sex-specific risk management strategy for preventing atherosclerosis.

\section{Abbreviations}

aOR: Adjusted odds ratio; BMI: Body mass index; CAD: Coronary artery disease; CIMT: Carotid intima-media thickness; CVD: Cardiovascular disease; CKD:
Chronic kidney disease; DM: Diabetes mellitus; eGFR: Estimated glomerular filtration rate; FBG: Fasting blood glucose; HTN: Hypertension; HOMA-IR: Homeostasis model assessment of IR; HDL: High-density lipoprotein; hsCRP: High-sensitivity C-reactive protein; HbA1c: Hemogloblin A1; ILAS: I-Lan Longitudinal Aging Study; IR: Insulin resistance; LDL: Low-density lipoprotein; Mets: Metabolic syndrome; SA: Subclinical atherosclerosis; TyG: Triglyceride glucose; T-Chol:Total cholesterol;T2DM: Type 2 diabetes mellitus; TG: Triglyceride.

\section{Supplementary Information}

The online version contains supplementary material available at https://doi. org/10.1186/s12933-021-01391-7.

Additional file 1: Table S1. Correlation coefficients of TyG index and the carotid intima-media thickness with other cardiovascular risk factors in whole population.

Additional file 2: Table S2. Baseline characteristics according to lower and higher TyG index in diabetic population stratified by gender.

\section{Acknowledgements}

Not applicable.

\section{Authors' contributions}

The dataset was collected using LYW. Data were interpreted and analyzed by LYW and TCT with help from HPH. The manuscript was drafted by LYW and $\mathrm{HPH}$. All authors read and approved the final manuscript.

\section{Funding}

This study was supported in part by research grants from the Novel Bioengineering and Technological Approaches to Solve Two Major Health Problems in Taiwan program. It was sponsored by the Taiwan Ministry of Science and Technology Academic Excellence Program (MOST 108-2633-B-009-001), Taipei Veterans General Hospital (VGH-V100E2-002 and VGHUST103-G7-2-1), the National Taiwan University Hospital, Hsinchu Branch (107-HCH0O2 and 108-HCH004), and the Ministry of Science and Technology (MOST-1052314-B-002-119, 106-2314-B-002-173-MY3, MOHW 106-TDU-B-211-113001). The Funding institutions took no part in the study design, data collection or analysis, publication intent, or manuscript preparation.

\section{Availability of data and materials}

The datasets used and analyzed during the current study are available from the corresponding author upon request.

\section{Declarations}

\section{Ethics approval and consent to participate}

This study was approved by the Research Ethics Committee of Taipei Veterans General Hospital. Written informed consent was obtained from all patients or their legal representatives.

\section{Consent for publication}

No published individual participant data were reported that would require consent from the participants.

\section{Competing interests}

The authors declare that they have no competing interests.

\section{Author details}

${ }^{1}$ Division of Interventional Cardiology, Cardiovascular Center, Taichung Veterans General Hospital, 1650 Taiwan Boulevard Sect. 4, Taichung, Taiwan. ${ }^{2}$ Division of Cardiology, Department of Medicine, Taipei Veterans General Hospital, Taipei, Taiwan. ${ }^{3}$ Present Address: Institute of Clinical Medicine, Cardiovascular Research Center, National Yang Ming Chiao Tung University, Taipei, Taiwan. ${ }^{4}$ Department of Critical Care Medicine, Taipei Veterans General Hospital, Taipei, Taiwan. ${ }^{5}$ Center for Geriatrics and Gerontology, Taipei Veterans General Hospital, Taipei, Taiwan. ${ }^{6}$ Aging and Health Research Center, National Yang Ming Chiao Tung University, Taipei, Taiwan. ${ }^{7}$ Institute of Public Health, National Yang Ming Chiao Tung University, Taipei, Taiwan. ${ }^{8}$ Taipei Municipal Gan-Dau 
Hospital, Taipei, Taiwan. ${ }^{9}$ Taipei Heart Institute, Taipei Medical University, Taipei, Taiwan. ${ }^{10}$ Division of Cardiology, Heart Center, Cheng-Hsin General Hospital, Taipei, Taiwan.

Received: 29 July 2021 Accepted: 22 September 2021 Published online: 13 October 2021

\section{References}

1. Taylor R. Type 2 diabetes: etiology and reversibility. Diabetes Care. 2013;36(4):1047-55.

2. Cleland SJ, Fisher BM, Colhoun HM, Sattar N, Petrie JR. Insulin resistance in type 1 diabetes: what is 'double diabetes' and what are the risks? Diabetologia. 2013;56(7):1462-70.

3. Adeva-Andany MM, Martínez-Rodríguez J, González-Lucán M, FernándezFernández C, Castro-Quintela E. Insulin resistance is a cardiovascular risk factor in humans. Diabetes Metab Syndr. 2019;13(2):1449-55.

4. Liu A, Abbasi F, Reaven GM. Adiposity indices in the prediction of metabolic abnormalities associated with cardiovascular disease in nondiabetic adults. Nutr Metab Cardiovasc Dis. 2011;21(8):553-60.

5. Wallace TM, Levy JC, Matthews DR. Use and abuse of HOMA modeling. Diabetes Care. 2004;27(6):1487-95.

6. Simental-Mendía LE, Rodríguez-Morán M, Guerrero-Romero F. The product of fasting glucose and triglycerides as surrogate for identifying insulin resistance in apparently healthy subjects. Metab Syndr Relat Disord. 2008;6(4):299-304.

7. da Silva A, Caldas APS, Hermsdorff HHM, Bersch-Ferreira ÂC, Torreglosa CR, Weber B, Bressan J. Triglyceride-glucose index is associated with symptomatic coronary artery disease in patients in secondary care. Cardiovasc Diabetol. 2019;18(1):89.

8. Zhao Q, Zhang TY, Cheng YJ, Ma Y, Xu YK, Yang JQ, Zhou YJ. Impacts of triglyceride-glucose index on prognosis of patients with type 2 diabetes mellitus and non-ST-segment elevation acute coronary syndrome: results from an observational cohort study in China. Cardiovasc Diabetol. 2020;19(1):108.

9. Nezu T, Hosomi N, Aoki S, Matsumoto M. Carotid intima-media thickness for atherosclerosis. J Atheroscler Thromb. 2016;23(1):18-31.

10. Stein JH, Korcarz CE, Hurst RT, Lonn E, Kendall CB, Mohler ER, Najjar SS, Rembold CM, Post WS. Use of carotid ultrasound to identify subclinical vascular disease and evaluate cardiovascular disease risk: a consensus statement from the American Society of Echocardiography Carotid Intima-Media Thickness Task Force. Endorsed by the Society for Vascular Medicine. J Am Soc Echocardiography Off Publ Am Soc Echocardiography. 2008;21(2):93-111.

11. Altin C, Sade LE, Gezmis E, Ozen N, Duzceker O, Bozbas H, Eroglu S, Muderrisoglu $\mathrm{H}$. Assessment of subclinical atherosclerosis by carotid intimamedia thickness and epicardial adipose tissue thickness in prediabetes. Angiology. 2016;67(10):961-9.

12. Sinning C, Wild PS, Echevarria FM, Wilde S, Schnabel R, Lubos E, Herkenhoff S, Bickel C, Klimpe S, Gori T, et al. Sex differences in early carotid atherosclerosis (from the community-based Gutenberg-Heart Study). Am J Cardiol. 2011;107(12):1841-7.

13. Yao L, Folsom AR, Alonso A, Lutsey PL, Pankow JS, Guan W, Cheng S, Lederle FA, Tang W. Association of carotid atherosclerosis and stiffness with abdominal aortic aneurysm: The atherosclerosis risk in communities (ARIC) study. Atherosclerosis. 2018:270:110-6.

14. Kokubo Y, Watanabe M, Higashiyama A, Nakao YM, Nakamura F, Miyamoto Y. Impact of intima-media thickness progression in the common carotid arteries on the risk of incident cardiovascular disease in the suita study. J Am Heart Assoc. 2018;7(11):e007720. https://doi.org/10.1161/ JAHA.117.007720.

15. Juutilainen A, Kortelainen S, Lehto S, Rönnemaa T, Pyörälä K, Laakso M. Gender difference in the impact of type 2 diabetes on coronary heart disease risk. Diabetes Care. 2004;27(12):2898-904.

16. Liu LK, Lee WJ, Chen LY, Hwang AC, Lin MH, Peng LN, Chen LK. Sarcopenia, and its association with cardiometabolic and functional characteristics in Taiwan: results from I-Lan Longitudinal Aging Study. Geriatr Gerontol Int. 2014;14(Suppl 1):36-45.
17. Levey AS, Stevens LA, Schmid CH, Zhang YL, Castro AF 3rd, Feldman HI, Kusek JW, Eggers P, Van Lente F, Greene T, et al. A new equation to estimate glomerular filtration rate. Ann Intern Med. 2009;150(9):604-12.

18. Fitzmaurice C, Abate D, Abbasi N, Abbastabar H, Abd-Allah F, AbdelRahman O, Abdelalim A, Abdoli A, Abdollahpour I, Abdulle ASM, et al. Global, regional, and national cancer incidence, mortality, years of life lost, years lived with disability, and disability-adjusted life-years for 29 cancer groups, 1990 to 2017: a systematic analysis for the global burden of disease study. JAMA Oncol. 2019:5(12):1749-68.

19. Lee SB, Ahn CW, Lee BK, Kang S, Nam JS, You JH, Kim MJ, Kim MK, Park JS. Association between triglyceride glucose index and arterial stiffness in Korean adults. Cardiovasc Diabetol. 2018;17(1):41.

20. Zhang Y, Ding X, Hua B, Liu Q, Gao H, Chen H, Zhao XQ, Li W, Li H. High triglyceride-glucose index is associated with poor cardiovascular outcomes in nondiabetic patients with ACS with LDL-C below $1.8 \mathrm{mmol} / \mathrm{L}$. J Atheroscler Thromb. 2021. https://doi.org/10.1016/j.numecd.2020.07.041.

21. Kanters SD, Algra A, van Leeuwen MS, Banga JD. Reproducibility of in vivo carotid intima-media thickness measurements: a review. Stroke. 1997;28(3):665-71.

22. Hodis HN, Mack WJ, LaBree L, Selzer RH, Liu CR, Liu CH, Azen SP. The role of carotid arterial intima-media thickness in predicting clinical coronary events. Ann Intern Med. 1998;128(4):262-9.

23. Dijk JM, van der GraafY, Bots ML, Grobbee DE, Algra A. Carotid intima-media thickness and the risk of new vascular events in patients with manifest atherosclerotic disease: the SMART study. Eur Heart J. 2006;27(16):1971-8

24. Mohan A, Sada S, Kumar BS, Sarma KVS, Devi BV, Rao PVLNS, Rajasekhar D, Katyarmal DT. Subclinical atherosclerosis in patients with rheumatoid arthritis by utilizing carotid intima-media thickness as a surrogate marker. Indian J Med Res. 2014;140(3):379-86.

25. Ormazabal V, Nair S, Elfeky O, Aguayo C, Salomon C, Zuñiga FA. Association between insulin resistance and the development of cardiovascular disease. Cardiovasc Diabetol. 2018;17(1):122.

26. Gast KB, Tjeerdema N, Stijnen T, Smit JW, Dekkers OM. Insulin resistance and risk of incident cardiovascular events in adults without diabetes: meta-analysis. PloS ONE. 2012;7(12):e52036.

27. Guerrero-Romero F, Simental-Mendía LE, González-Ortiz M, MartínezAbundis E, Ramos-Zavala MAG, Hernández-González SO, Jacques-Camarena $\mathrm{O}$, Rodríguez-Morán $\mathrm{M}$. The product of triglycerides and glucose, a simple measure of insulin sensitivity. Comparison with the euglycemichyperinsulinemic clamp. J Clin Endocrinol Metab. 2010;95(7):3347-51.

28. Li S, Guo B, Chen H, Shi Z, Li Y, Tian Q, Shi S. The role of the triglyceride (triacylglycerol) glucose index in the development of cardiovascular events: a retrospective cohort analysis. Sci Rep. 2019;9(1):7320.

29. Park B, Lee YJ, Lee HS, Jung DH. The triglyceride-glucose index predicts ischemic heart disease risk in Koreans: a prospective study using National Health Insurance Service data. Cardiovasc Diabetol. 2020;19(1):210.

30. Logue J, Walker JJ, Colhoun HM, Leese GP, Lindsay RS, McKnight JA, Morris AD, Pearson DW, Petrie JR, Philip S, et al. Do men develop type 2 diabetes at lower body mass indices than women? Diabetologia. 2011:54(12):3003-6.

31. de Ritter R, de Jong M, Vos RC, van der Kallen CJH, Sep SJS, Woodward $M$, Stehouwer CDA, Bots ML, Peters SAE. Sex differences in the risk of vascular disease associated with diabetes. Biol Sex Differ. 2020;11(1):1.

32. Satish M, Saxena SK, Agrawal DK. Adipokine dysregulation and insulin resistance with atherosclerotic vascular disease: metabolic syndrome or independent sequelae? J Cardiovasc Transl Res. 2019;12(5):415-24.

33. Tack CJ, Smits P, Willemsen JJ, Lenders JW, Thien T, Lutterman JA. Effects of insulin on vascular tone and sympathetic nervous system in NIDDM. Diabetes. 1996:45(1):15-22.

34. Fonseca VA. Insulin resistance, diabetes, hypertension, and renin-angiotensin system inhibition: reducing risk for cardiovascular disease. J Clin Hypertens. 2006;8(10):713-20.

35. Du T, Fernandez C, Barshop R, Guo Y, Krousel-Wood M, Chen W, Qi L, Harville E, Mauvais-Jarvis F, Fonseca V, et al. Sex differences in cardiovascular risk profile from childhood to midlife between individuals who did and did not develop diabetes at follow-up: The Bogalusa Heart Study. Diabetes Care. 2019;42(4):635-43.

36. Geer EB, Shen W. Gender differences in insulin resistance, body composition, and energy balance. Gend Med. 2009;6 Suppl 1(Suppl 1):60-75. 
37. Karelis AD, St-Pierre DH, Conus F, Rabasa-Lhoret R, Poehlman ET. Metabolic and body composition factors in subgroups of obesity: what do we know? J Clin Endocrinol Metab. 2004;89(6):2569-75.

38. Sattar N, Gill JM. Type 2 diabetes as a disease of ectopic fat? BMC Med. 2014;12:123.

39. Kvist H, Chowdhury B, Grangård U, Tylén U, Sjöström L. Total and viscera adipose-tissue volumes derived from measurements with computed tomography in adult men and women: predictive equations. Am J Clin Nutr. 1988;48(6):1351-61.

40. Lemieux S, Prud'homme D, Bouchard C, Tremblay A, Després JP. Sex differences in the relation of visceral adipose tissue accumulation to total body fatness. Am J Clin Nutr. 1993;58(4):463-7.

41. Power ML, Schulkin J. Sex differences in fat storage, fat metabolism, and the health risks from obesity: possible evolutionary origins. Br J Nutr. 2008;99(5):931-40.

42. de Mutsert R, Gast K, Widya R, de Koning E, Jazet I, Lamb H, le Cessie S, de Roos A, Smit J, Rosendaal F, et al. Associations of abdominal subcutaneous and visceral fat with insulin resistance and secretion differ between men and women: the Netherlands Epidemiology of Obesity Study. Metab Syndr Relat Disord. 2018;16(1):54-63.

43. Tiano JP, Mauvais-Jarvis F. Importance of oestrogen receptors to preserve functional $\beta$-cell mass in diabetes. Nat Rev Endocrinol. 2012;8(6):342-51.
44. Duncan AC, Lyall H, Roberts RN, Petrie JR, Perera MJ, Monaghan S, Hart DM, Connell JM, Lumsden MA. The effect of estradiol and a combined estradiol/progestagen preparation on insulin sensitivity in healthy postmenopausal women. J Clin Endocrinol Metab. 1999;84(7):2402-7.

45. Mattiasson I, Rendell M, Törnquist C, Jeppsson S, Hulthén UL. Effects of estrogen replacement therapy on abdominal fat compartments as related to glucose and lipid metabolism in early postmenopausal women. Horm Metab Res Horm Stoffwechs Horm Metab. 2002;34(10):583-8

46. El Khoudary SR, Shields KJ, Janssen I, Hanley C, Budoff MJ, BarinasMitchell E, Everson-Rose SA, Powell LH, Matthews KA. Cardiovascular fat, menopause, and sex hormones in women: the SWAN Cardiovascular Fat Ancillary Study. J Clin Endocrinol Metab. 2015;100(9):3304-12.

47. Tramunt B, Smati S, Grandgeorge N, Lenfant F, Arnal JF, Montagner A, Gourdy P. Sex differences in metabolic regulation and diabetes susceptibility. Diabetologia. 2020;63(3):453-61.

\section{Publisher's Note}

Springer Nature remains neutral with regard to jurisdictional claims in published maps and institutional affiliations.
Ready to submit your research? Choose BMC and benefit from:

- fast, convenient online submission

- thorough peer review by experienced researchers in your field

- rapid publication on acceptance

- support for research data, including large and complex data types

- gold Open Access which fosters wider collaboration and increased citations

- maximum visibility for your research: over 100M website views per year

At BMC, research is always in progress.

Learn more biomedcentral.com/submissions 